memo (2011) Vol. 4: 3

DOI 10.1007/s12254-011-0250-y

Printed in Austria

(C) Springer-Verlag 2011

\section{Valentina Tzekova}

It is with deepest regret that we inform you about the death of our colleague and friend Valentina Tzekova.

Prof. Valentina Tzekova was a member of the Editorial Board of memo. Her death really took us by surprise and shocked us, as we still remember quite clearly her enthusiasm and engagement when acting as guest editor for issue 2/2010 of memo to the topic "Current Treatment of Gastrointestinal Stromal Tumours". She always knew how to motivate her team and everybody who worked with her. For several years now, it has been memo's aim to open towards Eastern countries and here, Valentina Tzekova representing her home country Bulgaria alway came up with some valuable contributions. Therefore she will leave a wide gap as she was a highly qualified member of the medical staff of the University Hospital in Sofia and we will all miss her from an emotional as well as scientific point of view.

Our thoughts are with Valentina and we want to express our sadness and condolences to her family.

Wolfgang Hilbe Editor in Chief 